\title{
Letter to the editor: Measles cases among fully vaccinated persons
}

Yuzo Arima ${ }^{1}$, Kazunori Oishi ${ }^{1}$

1. Infectious Disease Surveillance Center, National Institute of Infectious Diseases, Tokyo, Japan

Correspondence: Yuzo Arima (arima@niid.go.jp)

Citation style for this article:

Arima Yuzo, Oishi Kazunori. Letter to the editor: Measles cases among fully vaccinated persons. Euro Surveill. 2018;23(34):pii=1800449. https://doi. org/10.2807/1560-7917.ES.2018.23.34.1800449

To the editor: We read with great interest the rapid communication by Bernadou et al. [1] regarding the measles outbreak in France. In particular, we noted that the proportion of measles cases who were fully vaccinated (i.e. with two doses of measles-mumps-rubellacontaining vaccine) was higher (14\%) than what was observed in France during the much larger epidemic that occurred between 2008 and 2011 (3-4\%). As the authors state, rising proportions of vaccinated cases have been observed recently in several countries [2-4].

Importantly, increasing proportions of vaccinated measles cases can be interpreted by the public or the media, incorrectly, as an indication of an ineffective vaccine. We appreciate that the authors state that further investigation is needed, and we would also like to comment on this 'paradox'.

While measles-containing vaccine (MCV) is highly effective, a small proportion of vaccinated persons (i.e. $3 \%$ [5]) exposed to the virus are known to manifest as measles despite having been vaccinated with two doses of MCV. With increased vaccination coverage in the general population, the number of fully vaccinated individuals increases, and proportionate to this increase, the frequency of fully vaccinated measles cases would be expected to increase (since a small percent of the fully vaccinated are known to contract measles), as long as the measles virus circulates. Moreover, as the number of unvaccinated individuals remaining in the population decreases, in proportion to this decline, the frequency of unvaccinated measles cases is expected to decrease (assuming that all other factors remain unchanged; herd protection could further decrease the likelihood of exposure to a measles case for the few unvaccinated persons). Thus, even with a highly effective vaccine, proportionate to the increase in the vaccinated and decrease in the unvaccinated, the proportion of fully vaccinated cases would, on average, be expected to increase (here, we are not considering cases imported from endemic areas or population-mixing dynamics).
However, as the absolute risk of measles is very low among those fully vaccinated, with increased vaccination coverage, we would expect a decrease in the incidence of cases in the general population. Even if the relative risk of measles in the fully vaccinated vs unvaccinated were constant, the increased weight of the fully vaccinated in the population would decrease the overall incidence. Compared with the considerably larger epidemic that occurred between 2008 and 2011 in France [6], we wonder if the increase in the proportion of fully vaccinated cases is reflecting the increased vaccination coverage [4], given the smaller size of the current outbreak in France $[7,8]$. As the authors comment, further investigations are warranted, and analyses by birth cohort or specific population groups may be informative-for instance, for subpopulations where vaccination coverage is high, the proportion of fully vaccinated cases may be high, but the incidence of measles low.

Any interpretation of risk needs to consider denominators. In considering the proportion of cases fully vaccinated-which is only a proportion of vaccination status among the numerator of cases-we need to be mindful of the number of vaccinated and unvaccinated individuals in the underlying population. As an extreme hypothetical example, if $100 \%$ of the population were vaccinated twice, we might expect only about $3 \%$ of those to become cases, but we would see that all the cases were fully vaccinated. With increasing vaccination coverage, the visibility of vaccinated cases will increase, and requires careful interpretation.

Thus, although the phenomenon of increasing proportion of fully vaccinated cases with increased vaccine coverage may seem counterintuitive [4], in the context of decreased incidence, this is expected. While waning immunity and increased sensitivity of investigations (i.e. detecting milder measles cases who are more likely to have been vaccinated $[2,5]$ ) may also explain some of the increased proportion of vaccinated cases, 
even in the absence of such conditions, this phenomenon would not be surprising. We commend Bernadou et al. for their rapid communication and add a brief epidemiological commentary, lest some in the media/ public erroneously conclude that measles vaccine is not effective. Such misinterpretation can have negative implications for vaccine uptake, and reminds us of the importance of risk communication in public health.

\section{Conflict of interest}

None declared.

\section{Authors' contributions}

Conception: YA; wrote first draft: YA; reviewed, edited, and approved final version: $Y A$ and $K O$

\section{References}

1. Bernadou A, Astrugue C, Méchain M, Le Galliard V, VerdunEsquer C, Dupuy F, et al. Measles outbreak linked to insufficient vaccination coverage in Nouvelle-Aquitaine Region, France, October 2017 to July 2018. Euro Surveill. 2018;23(30):1800373. https://doi.org/10.2807/1560-7917. ES.2018.23.30.1800373 PMID: 30064543

2. Rita SM, Mariana PD, Soraia A, Ivo C, Ana S, Isabel A, et al. Measles outbreak in a tertiary level hospital, Porto, Portugal, 2018: challenges in the post-elimination era. Euro Surveill. 2018;23(20): pii=18-00224. https://doi.org/10.2807/1560-7917. ES.2018.23.20.18-00224

3. Hahné SJ, Nic Lochlainn LM, van Burgel ND, Kerkhof J, Sane J, Yap KB, et al. Measles Outbreak Among Previously Immunized Healthcare Workers, the Netherlands, 2014. J Infect Dis. 2016;214(12):1980-6. https://doi.org/10.1093/infdis/jiw480 PMID: 27923955

4. Althaus CL, Salathé M. Measles Vaccination Coverage and Cases among Vaccinated Persons. Emerg Infect Dis. 2015;21(8):1480-1. . Available from: https://dx.doi.org/10.3201/ eid2108.150284 https://doi.org/10.3201/eid2108.150284 PMID: 26196331

5. Centers for Disease Control and Prevention (CDC). National Center for Immunization and Respiratory Diseases, Division of Viral Diseases. Frequently Asked Questions about Measles in the U.S. Atlanta: CDC; [Accessed 13 Aug 2018]. Available from: https://www.cdc.gov/measles/about/faqs.html

6. Antona D, Lévy-Bruhl D, Baudon C, Freymuth F, Lamy M, Maine C, et al. Measles elimination efforts and 2008-2011 outbreak, France. Emerg Infect Dis. 2013;19(3):357-64. https://doi. org/10.3201/eid1903.121360 PMID: 23618523

7. European Centre for Disease Prevention and Control (ECDC). Monthly measles and rubella monitoring report, July 2018. Stockholm: ECDC; 2018. Available from: https://ecdc.europa. eu/sites/portal/files/documents/Monthly-Measles-Rubellamonitoring-report-July-2018-1.pdf

8. World Health Organization (WHO) Regional Office for Europe. WHO EpiData, No. 6/2018. Copenhagen: WHO. 5 Jul 2018. Available from: http://www.euro.who.int/en/health-topics/ disease-prevention/vaccines-and-immunization/publications/ surveillance-and-data/who-epidata/who-epidata,-no-62018

\section{License and copyright}

This is an open-access article distributed under the terms of the Creative Commons Attribution (CC BY 4.0) Licence. You may share and adapt the material, but must give appropriate credit to the source, provide a link to the licence, and indicate if changes were made.

This article is copyright of the authors or their affiliated institutions, 2018. 